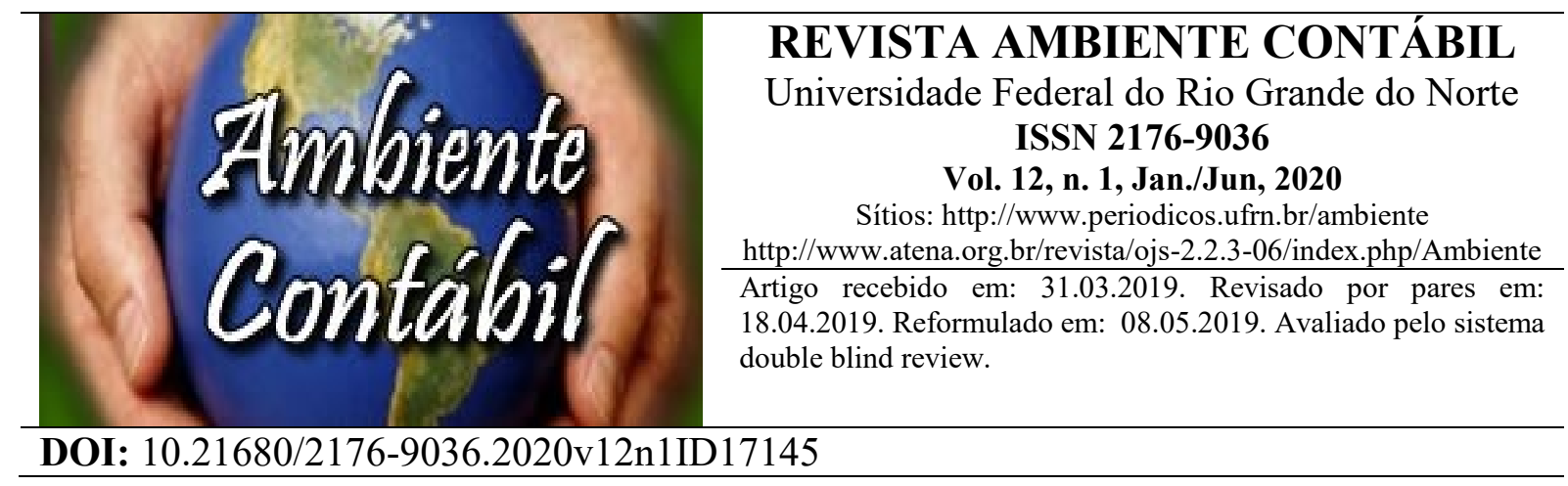

Mapeamento de competências: necessidades de aprimoramento de analistas periciais em contabilidade do Ministério Público Federal

Competency mapping: improvement needs of analysts from the area of expertise in accounting at the Federal Public Ministry

Mapeo de Competencias: necesidades de formación de analistas del área de pericia y especialidad en contabilidad en el Ministerio Público Federal

\title{
Autores
}

\section{Ariel Prates}

Mestre em Contabilidade (Universidade Federal do Rio Grande do Sul) - Endereço: Rua Padre Ambrosio Schupp, 194, São Leopoldo, RS - (51) 99353-1048 - Identificadores (ID):

ORCID iD: https://orcid.org/0000-0001-5470-2428

Lattes: http://lattes.cnpq.br/6619445436842581.

E-mail: ariel_prates@hotmail.com

\section{Jonatas Dutra Sallaberry}

Doutorando em Contabilidade (Universidade Federal de Santa Catarina) - Endereço: UFSC PPGC - CSE, Bloco F, Campus Trindade, 88040-970 - Florianópolis, SC - Telefone: (41) 98496-6447 - Identificadores (ID):

ORCID iD: https://orcid.org/0000-0001-7492-727X

REDALYC: redalyc.org/ autor.oa?id=21683

Lattes: http://lattes.cnpq.br/9920574928553347

Google Analytics UA-111870382-1

E-mail: jonatas.sallaberry@hotmail.com

\section{Leonardo Flach}

Pós-doutor em Contabilidade e Finanças (Massachusetts Institute of Technology - MIT/EUA). Doutor em Administração (UFRGS). Professor do Programa de Pós-graduação em Contabilidade (UFSC) - Endereço: Universidade Federal de Santa Catarina PPGC - CSE, Bloco F, Campus Trindade, 88040-970 - Florianópolis, SC - Identificadores (ID):

ORCID iD: https://orcid.org/0000-0002-4316-0704

Lattes: http://lattes.cnpq.br/8428386728078124

E-mail: leonardo.flach@gmail.com 
Ariel Prates, Jonatas Dutra Sallaberry, Leonardo Flach, Ivam Ricardo Peleias e Romina Batista de Lucena de Souza

\section{Ivam Ricardo Peleias}

Doutor em Ciências Contábeis (FEA-USP). Professor e pesquisador (Fundação Escola de Comércio Álvares Penteado - FECAP) - Endereço: Avenida Liberdade, n. ${ }^{\circ}$ 532. Liberdade. São Paulo - SP, CEP: 01502-001 - Identificadores (ID):

ORCID iD: https://orcid.org/0000-0003-3502-964X

Lattes: http://lattes.cnpq.br/1583907056732686.

E-mail: ivamrp@fecap.br

\section{Romina Batista de Lucena de Souza}

Doutora em Economia do Desenvolvimento (UFRGS). Professora do Programa de Pósgraduação em Contabilidade (UFRGS) - Endereço: Av. João Pessoa, 52, Sala 28-I, Centro, 90040-000 - Porto Alegre, RS. Telefone: (51) 33083487 - Identificadores (ID):

ORCID iD: https://orcid.org/0000-0001-8282-262X

Lattes: http://lattes.cnpq.br/1027011694846632

E-mail: rominabls@gmail.com

(Artigo apresentado no AdCont 2018: IX Congresso Nacional de Administração e Contabilidade)

\section{Resumo}

Objetivo: $\mathrm{O}$ estudo tem como objetivo analisar as competências dos analistas da área pericial contábil lotados no Ministério Público Federal (MPF), de forma a apresentar por nível de importância aquelas que possuem maior necessidade de aprimoramento.

Metodologia: O desenvolvimento da pesquisa ocorreu por meio da tipologia descritiva, com abordagem quantitativa. A técnica empregada foi pesquisa survey, a partir de um questionário estruturado com 37 questões, aplicados em escala tipo Likert de sete pontos. No instrumento foram apresentadas questões sobre a importância, o domínio de competências e seu impacto no desempenho profissional.

Resultados: Os resultados indicam que apenas quatro competências possuem domínio satisfatório por parte dos respondentes, e que cinco competências carecem maior aprimoramento: capacitação continuada, técnicas de investigação de fraudes, redação, conhecimento jurídico e pensar como malfeitor. As competências comportamentais foram consideradas mais importantes do que as técnicas. Ainda assim, algumas competências importantes no contexto internacional tiveram médias baixas no contexto brasileiro.

Contribuições do Estudo: $O$ estudo permite conhecer as competências dos analistas periciais do MPF sob os aspectos de importância, domínio e impacto no desempenho profissional. Os resultados podem ser empregados para o desenvolvimento de ações de capacitação na instituição da amostra bem como para outras instituições que dispõe de quadro semelhante. $\mathrm{O}$ estudo também pode ser replicado como diagnóstico para outras instituições e quadros de profissionais de perícia contábil e forense, servindo de parâmetro de comparabilidade.

Palavras-chave: Competências. Perícia Contábil. Contabilidade Forense.

\section{Abstract}


Ariel Prates, Jonatas Dutra Sallaberry, Leonardo Flach, Ivam Ricardo Peleias e Romina Batista de Lucena de Souza

Purpose: The objective of this study is to analyze the skills of analysts in the accounting expert area that are filled out by the Federal Public Prosecutor's Office (MPF), in order to present by level of importance those that have the greatest need for improvement.

Methodology: The research was carried out through the descriptive typology, with a quantitative approach. The technique employed was a survey, based on a structured questionnaire with 37 questions, applied in a seven-point Likert scale. The instrument presented questions about the importance, the domain of competencies and their impact on professional performance.

Results: The results indicate that only four competences have a satisfactory domain on the part of the respondents, and that five competences need further improvement: continuous training, fraud investigation techniques, writing, legal knowledge and thinking as a wrongdoer. Behavioral skills were considered more important than techniques. Nevertheless, some important competences in the international context had low averages in the Brazilian context.

Contributions of the Study: The study allows to know the skills of the MPF expert analysts under aspects of importance, mastery and impact on professional performance. The results can be used for the development of training actions in the institution of the sample as well as for other institutions that have a similar framework. The study can also be replicated as a diagnostic for other institutions and cadres of forensic and accounting experts, serving as a benchmark.

Keywords: Competencies. Accounting Skills. Forensic Accounting.

\section{Resumen}

Objetivo: El estudio tiene como objetivo analizar las competencias de los analistas del área pericial contable abarrotados en el Ministerio Público Federal (MPF), de forma a presentar por nivel de importancia aquellas que poseen mayor necesidad de perfeccionamiento.

Metodología: El desarrollo de la investigación ocurrió por medio de la tipología descriptiva, con abordaje cuantitativo. La técnica empleada fue investigación survey, a partir de un cuestionario estructurado con 37 cuestiones, aplicados a escala tipo Likert de siete puntos. En el instrumento se plantearon cuestiones sobre la importancia, el dominio de competencias y su impacto en el desempeño profesional.

Resultados: Los resultados indican que sólo cuatro competencias poseen dominio satisfactorio por parte de los encuestados, y que cinco competencias carecen mayor perfeccionamiento: capacitación continuada, técnicas de investigación de fraudes, redacción, conocimiento jurídico y pensar como malhechor. Las competencias de comportamiento se consideraron más importantes que las técnicas. Sin embargo, algunas competencias importantes en el contexto internacional tuvieron medias bajas en el contexto brasileño.

Contribuciones del Estudio: El estudio permite conocer las competencias de los analistas periciales del MPF bajo los aspectos de importancia, dominio e impacto en el desempeño profesional. Los resultados pueden ser empleados para el desarrollo de acciones de capacitación en la institución de la muestra así como para otras instituciones que disponen de cuadro semejante. El estudio también puede ser replicado como diagnóstico para otras instituciones y 
Ariel Prates, Jonatas Dutra Sallaberry, Leonardo Flach, Ivam Ricardo Peleias e Romina Batista de Lucena de Souza

cuadros de profesionales de pericia contable y forense, sirviendo de parámetro de comparabilidad.

Palabras clave: Competencias. Experiencia contable. Contabilidad Forense.

\section{Introdução}

O Brasil é o país com o maior número de processos per capita, fato que demonstra a complexidade e o tamanho do desafio que é montar e manter um sistema judiciário eficiente, justo e rápido, para atender à demanda (CNJ, 2011). Nesse cenário, cada vez mais se faz presente - e necessário - o trabalho do perito contábil como auxiliar da justiça.

Embora tenham a mesma recorrência em relação aos crimes do direito penal tradicional (como roubo e homicídio), os delitos nas mais altas instâncias da atividade econômica (como estelionato, corrupção e improbidade administrativa) são de menor difusão pública e, consequentemente, aparecem com menor frequência nos meios de comunicação (Veras, 2006). Nos últimos anos, os crimes de corrupção passaram a ter mais espaço na imprensa tradicional.

O Ministério Público Federal (MPF), instituição campo amostral deste estudo, ajuda a combater tais infrações e atua como titular da persecução penal. Ele pode instaurar inquérito civil, instaurar inquérito policial, requisitar diligências investigatórias, ou investigar, sob a tutela dos Procuradores da República, membros desse órgão.

Em atuação conjunta com os Procuradores no MPF, os analistas da área de perícia com especialidade em contabilidade, devidamente registrados, possuem como atribuições básicas: a realização de perícias, vistorias e exames; a coleta e análise de dados documentais; a prestação de informações técnicas sob a forma de pareceres, laudos e relatórios, indicando a fundamentação técnica e os métodos aplicados; e a atuação em processos administrativos e judiciais como assistente técnico (Brasil, 2013).

Diante da diversidade de atuações do Ministério Público e considerando a amplitude dos casos de competência federal, intensifica-se a importância da pesquisa com uma amostra de profissionais responsáveis pela produção da prova pericial, que usam como base de seu trabalho o conhecimento científico e as inovações tecnológicas aplicadas (Rodrigues, Silva, \& Truzzi, 2010).

Esses analistas precisam possuir determinadas competências para o exercício de suas atividades, que incluem as capacidades intelectuais, os conhecimentos teóricos e práticos, as capacidades comportamentais, e atitudes frente às necessidades impostas pelo serviço desempenhado (Silva, 2014). Isto posto, busca-se com a presente pesquisa responder a seguinte questão: Quais são as competências em que há maior necessidade de aprimoramento por parte de um analista da área de perícia e especialidade em contabilidade do Ministério Público Federal? Assim, esse estudo tem como objetivo analisar as competências dos analistas da área pericial contábil lotados no Ministério Público Federal (MPF), de forma a apresentar aquelas que possuem maior necessidade de aprimoramento por nível de importância, domínio e impacto.

Este estudo se justifica de forma prática e teórica, pois os resultados podem revelar um perfil das competências necessárias ao desempenho das atribuições de tal analista. $\mathrm{O}$ estudo permite conhecer as competências dos analistas periciais do MPF sob os aspectos de importância, domínio e impacto no desempenho profissional. Os resultados podem ser empregados para o desenvolvimento de ações de capacitação na instituição da amostra bem como para outras instituições que dispõe de quadro semelhante. A correção de deficiências pode 
proporcionar melhorias significativas de desempenho por parte dos analistas da área de pericial contábil. Isto aceleraria e aumentaria a qualidade dos serviços prestados. Por consequência, poderia melhorar a qualidade da prestação dos serviços públicos.

Este estudo não busca revelar a atuação operacional desses profissionais, nem acrescentar pontos à literatura referentes às definições de contabilidade forense e perícia contábil. Todavia, aplica os termos da literatura vigente em competências de contabilidade forense ao contexto da amostra. $\mathrm{O}$ estudo também pode ser replicado como diagnóstico para outras instituições e quadros de profissionais de perícia contábil e forense, servindo de parâmetro de comparabilidade.

\section{Referencial Bibliográfico}

Os Analistas do Ministério Público Federal (MPF) respondem diretamente aos Procuradores da República. Esses profissionais atuam em primeira instância perante o Juiz Federal. Quando promovidos a Procuradores Regionais da República, eles atuam em segunda instância, ante o Tribunal Regional Federal. E nos mais altos cargos dessa carreira, os Subprocuradores-Gerais da República e o Procurador-Geral da República (nomeado pelo Presidente), atuam perante o Supremo Tribunal de Justiça (STJ) e o Supremo Tribunal Federal (STF) [CF, 1988]. A atuação do Analista do MPF pode ser requerida em qualquer instância.

O MPF intervém em causas nas quais a Constituição considera haver interesse federal. Ele pode atuar judicialmente como fiscal da lei, cível e criminal. Ele pode também agir extrajudicialmente, para recomendações e promoção de acordos por meio dos termos de ajuste de conduta (Brasil, 2017a). Assim, o MPF pode atuar como acusador, ou como custos legis (Brasil, 1993), sendo fiscalizador e imparcial.

No intuito de tornar o MPF um órgão estruturado e organizado, no ano de 2012 começou a ser realizada uma modernização no órgão (Brasil, 2017b). $O$ foco desta modernização era de agilizar a tomada de decisão e adequar a gestão de pessoas, de materiais e de recursos às necessidades das atividades institucionais, unindo as áreas administrativa e finalística (Brasil, 2017b).

Esse processo de modernização busca sempre um alinhamento com o planejamento estratégico institucional do órgão, que inclui a visão, missão e valores. As diretrizes buscam nortear as ações de cada integrante, sob a perspectiva da sociedade, processos internos, aprendizado e conhecimento (Brasil, 2017b). Em relação a aprendizagem e desenvolvimento de conhecimentos, é possível perceber que estão diretamente relacionados com a busca pelo desenvolvimento de conhecimentos, habilidades e atitudes dos membros e servidores, sendo essa a base do conceito de competências utilizado nessa pesquisa

\subsection{Competências}

O termo competência advém do latim competentia, que significa ser capaz (Silva, 2012a). De acordo com o autor, esse termo possui, na técnica jurídica, dupla aplicação. A primeira se refere à aptidão pela qual a pessoa pode exercitar ou fruir um direito. E a segunda é empregada no sentido de "poder", no sentido de que a pessoa possui autoridade legal para conhecer certos atos e deliberar a seu respeito.

Contudo, o conceito de competência que se explora na presente pesquisa está alinhado com a gestão de pessoas. Inicialmente, McClelland (1973) examinou o uso de testes de inteligência e aptidão nos processos de seleção de pessoas para cargos em uma organização, e

Revista Ambiente Contábil - UFRN - Natal-RN. v. 12, n. 1, p. 215 -233, Jan./Jun. 2020, ISSN 2176-9036. 
Ariel Prates, Jonatas Dutra Sallaberry, Leonardo Flach, Ivam Ricardo Peleias e Romina Batista de Lucena de Souza

iniciou um debate entre psicólogos e administradores norte-americanos sobre a definição do termo (Fleury, \& Fleury, 2001).

Posteriormente, Boyatzis (1982) definiu competência como um conjunto de características subjacentes de um indivíduo que estão relacionadas a um desempenho superior de suas atribuições. Fleury e Fleury (2004) complementam que um dos sentidos do termo é a designação de qualificações para uma pessoa realizar determinada tarefa. Porém, seu conceito ainda é abordado de forma polissêmica entre os pesquisadores (Mclagan, 1997), sendo, de certa forma, controvertido (Ruas, 2005), devido as várias áreas de conhecimento nas quais o termo é empregado (Shippmann et al., 2000).

Ressalta-se que não há acepções do termo competência sem que estejam totalmente erradas, e a variação ocorre em função de sua aplicação. Não há consenso na literatura, mas é possível constatar pontos de convergência entre as diferentes abordagens (Silva, 2014). Conhecimentos, habilidades e atitudes (CHA) são elementos que compõem a competência, representando, respectivamente, as dimensões cognitivas, psicomotoras e afetivas do trabalho (Carbone, Brandão, \& Leite, 2009; Durand, 1998; Fleury, \& Fleury, 2001), de forma a agregar valor para pessoas e organizações (Durand, 1998).

Esta tríade de qualidades já havia sido exposta anteriormente, quando foram inseridas no ambiente organizacional, redefinindo o conhecimento como "saber o que e por que fazer"; relaciona habilidade com "saber como fazer"; e associa atitude com "querer fazer" (Brandão, 2009). Magalhães e Borges-Andrade (2001) definem conhecimento como um conjunto organizado de informações que, se aplicado, torna possível o desempenho adequado de um trabalho; habilidade consiste na capacidade de realizar ações de trabalho apropriados para favorecer a realização das tarefas inerentes à função; e atitudes são as predisposições e os sentimentos do indivíduo sobre o seu trabalho, seus afazeres, e organização onde está inserido.

Leme (2005) e Reis (2003) classificam as competências em dois grandes grupos: técnicas e comportamentais. A primeira compreende as qualidades que um indivíduo necessita para desempenhar o seu papel, sendo expressa pelas letras " $\mathrm{C}$ " (saber o que e porque fazer) e " $\mathrm{H}$ " (saber como fazer) da sigla CHA. Para Nordhaug (1998), as competências técnicas estão relacionadas a métodos e técnicas criadas para conduzir uma atividade específica. O segundo grupo, das competências comportamentais, está relacionado com o "A" (querer fazer) dessa mesma sigla. Segundo Leme (2005), este grupo compreende as ações que um profissional precisa demonstrar como diferencial competitivo, impactando nos seus resultados. Para Pierry (2006 p. 39), são competências emocionais e afetivas, que incluem "a capacidade de se adaptar às mudanças impostas pela organização e lidar satisfatoriamente com as adversidades encontradas nas alterações de grau de complexidade e responsabilidade nas funções propostas". São qualidades interpessoais (Nordhaug, 1998). Esse tipo de competência está relacionada com a habilidade de lidar, de maneira eficaz, com relações interpessoais, o que inclui, por sua vez, dar e receber feedback, sendo uma capacidade que é aperfeiçoada com treinamento (Moscovia, 1981).

As competências comportamentais se tornaram mais valorizadas, possuindo maior importância em relação às competências técnicas para o alcance dos objetivos organizacionais (Silva, 2014). Nesse sentido, Reis (2003) expõe que recentemente as entrevistas para seleção de funcionários estão focando mais nas ações e resultados dos candidatos do que somente em seus conhecimentos e habilidades. 
Ariel Prates, Jonatas Dutra Sallaberry, Leonardo Flach, Ivam Ricardo Peleias e Romina Batista de Lucena de Souza

\subsection{Competências de Peritos Contábeis no Contexto Brasileiro}

O termo perito possui origem no latim, peritus, sendo sinônimo de experto, louvado e hábil (Mossin, 2013). Este profissional entende e conhece profundamente fatos contábeis, devido ao seu conhecimento e sua experiência. Por isso, perito é o profissional capaz de analisar, interpretar e evidenciar problemas, fatos e significados, com clareza e profundidade (Leitão Júnior, Slomski, Peleias, \& Mendonça, 2012; Santana, 1999).

Das qualidades profissionais inerentes ao referido perito, pode-se listar o conhecimento teórico-prático da ciência contábil, experiência em perícias, perspicácia e conhecimento interdisciplinar de ciências afins à Contabilidade, como a área de direito (Gonçalves, Machado, Machado, \& Zanolla, 2014; Sá, 2011;), eficiência em comunicação escrita, apresentar capacidade investigativa (Gonçalves et al., 2014), imparcialidade, honestidade, zelo e responsabilidade (Alberto, 2012).

Especificamente quanto aos peritos criminais da Polícia Federal da área financeira, Silva (2014) analisou a percepção de tais profissionais sobre as competências necessárias para o exercício de suas atividades. Ao realizar um levantamento com 86 peritos, o autor obteve 41 competências diferentes atribuíveis aos profissionais desta área, utilizando a escala tipo Likert de sete pontos.

Como resultados, Silva (2014) constatou que a capacidade de agir com honestidade é aquela com maior média de importância $(6,72$, considerada alta importância). Já a capacidade de buscar constantemente o preparo profissional, de modo a maximizar o desempenho competente de suas atribuições, teve média igual a 5,76 (alta importância). Mas o domínio foi a competência com o valor médio mais baixo das percepções sobre 41 competências analisadas, com média de 4,85 (média importância). Também se verificou que competências comportamentais são mais relevantes que as competências técnicas, considerando que aquelas possuem, em sua maioria, maiores médias de importância do que as competências comportamentais.

Por fim, o domínio de todas as competências encontradas está dentro de um nível adequado. Afinal, a atribuição com menor média teve pontuação 4,85 , e se enquadrou como médio domínio na escala adotada. Outro resultado encontrado pelo autor é que todas as competências atingiram importância superior do que 5 (alta importância).

\subsection{Competências de Contadores Forenses no Contexto Internacional}

O termo forense corresponde a forensis, que significa público. A sua origem do latim fórum, que significa foro, ou seja, local em que tribunais analisam as causas de determinada ação (Huatuco, 2007). A técnica forense possui o objetivo de trazer ao conhecimento público (para o lado de fora) ou para praça pública, a revelação de dados ou fatos ocorridos que de alguma forma acarretaram algum prejuízo a terceiros em favor de outros (Silva, 2012b).

Hegazy, Sangster, \& Kotb (2017) aplicaram um questionário com contadores forenses no Reino Unido, no intuito de verificar as competências mais importantes para essa profissão, e chegaram a uma amostra final de 56 questionários validados. Os autores analisaram apenas competências técnicas, compreendidas pelas letras " $\mathrm{C}$ " e " $\mathrm{H}$ " da tríade $C H A$, sem as competências comportamentais, representadas pela letra "A". Os resultados desta pesquisa foram que são consideradas as competências técnicas mais importantes: comunicação escrita,

Revista Ambiente Contábil - UFRN - Natal-RN. v. 12, n. 1, p. 215 - 233, Jan./Jun. 2020, ISSN 2176-9036. 
habilidades analíticas, comunicação oral, habilidades de investigação de fraude e a qualidade na apresentação dos resultados.

Já nos Estados Unidos, Davis, Farrell e Ogilby (2009) analisaram as características e competências necessárias para o contador forense norte-americano. Os autores aplicaram um questionário com uma amostra de estudantes, Procuradores e contadores públicos, e obtiveram respectivamente 50, 126 e 603 respostas em cada grupo, totalizando um montante de 779 respostas. Os resultados obtidos apontam que habilidades analíticas, ética, responsabilidade, curiosidade, perspicácia, persistência e ceticismo são as características e competências consideradas como mais importantes para a amostra analisada.

Okoye e Jugu (2010) aplicaram um questionário com estudantes de contabilidade, potenciais contadores forenses e potenciais usuários de serviços da contabilidade forense. Obedecendo a escala tipo Likert de cinco pontos, os autores obtiveram 200 questionários respondidos, e verificaram que as competências pensamento crítico, resolução de problemas desestruturados, flexibilidade investigativa, habilidade analítica e conhecimentos sobre a legislação são as mais importantes para a amostra analisada.

\section{Procedimentos de Pesquisa}

De natureza aplicada, esta pesquisa tem como característica fundamental, segundo Gil (2008, p. 27), o "interesse na aplicação, utilização e consequências práticas dos conhecimentos [...] está menos voltada para o desenvolvimento de teorias de valor universal que para a aplicação imediata numa realidade circunstancial".

Quanto a abordagem do problema, a pesquisa possui características quantitativas, já que há utilização de instrumentos estatísticos para o tratamento dos dados (Raupp, \& Beuren, 2006). Isto posto, os resultados dessa pesquisa são obtidos nas formas de percentual e algébrica, com o intuito de destacar características mais relevantes.

No que tange aos objetivos, esta pesquisa é descritiva, pois analisa e correlaciona fatos sem manipulá-los, analisa frequências, verifica a relação e conexão de fenômenos, suas naturezas e características (Cervo, Bervian, \& Silva, 2007). Quanto aos procedimentos, classifica-se como survey.

Realizou-se um pré-teste com um dos analistas do MPF, que não participou da amostra dessa pesquisa. Durante o pré-teste, verificou-se que havia competências suscitadas por ele que não constavam na literatura pesquisada. Por isso, incluiu-se suas sugestões no questionário final. Após o pré-teste, e da população de 44 analistas, 13 aceitaram participar nessa pesquisa, compondo, assim, uma amostra não-probabilística.

No que tange à coleta dos dados, optou-se pelo uso do questionário estruturado com 37 questões fechadas, cujas respostas seguem a escala Likert de sete pontos. Para cada questão, o respondente deveria atribuir, nota de a 1 a 7 , para a importância e o domínio da respectiva competência, conforme Tabela 1. 
Ariel Prates, Jonatas Dutra Sallaberry, Leonardo Flach, Ivam Ricardo Peleias e Romina Batista de Lucena de Souza

Tabela 1

Descrição da Escala Likert

\begin{tabular}{lll}
\hline Grau & \multicolumn{1}{c}{$\begin{array}{c}\text { Qual a importância desta } \\
\text { competência? }\end{array}$} & \multicolumn{1}{c}{ Qual seu domínio nesta competência? } \\
\hline 1 & Nenhuma importância/irrelevante & Não tenho domínio/não possuo a competência \\
\hline 2 & Muito pouca importância & Tenho muito pouco domínio da competência \\
\hline 3 & Pouca importância & Tenho pouco domínio da competência \\
\hline 4 & Média importância & Tenho médio domínio da competência \\
\hline 5 & Alta importância & Tenho alto domínio da competência (a possuo) \\
\hline 6 & Muito alta importância & Tenho muito alto domínio da competência \\
\hline 7 & Extrema importância (imprescindível) & Tenho pleno domínio da competência (a possuo com excelência) \\
\hline
\end{tabular}

Fonte: Adaptado de Silva (2014).

O formulário foi elaborado com base na literatura nacional e internacional, compreendendo, em sua maioria, estudos aplicados a peritos contábeis e peritos criminais federais da área 1 da Polícia Federal (âmbito nacional) e contadores forenses (Estados Unidos, Reino Unido e Nigéria). As questões foram construídas a partir da tradução literal dos instrumentos nativos de língua estrangeira por especialista em Letras. Em seguida, os itens traduzidos foram agrupados com os itens dos instrumentos em língua portuguesa por um dos autores, devido a similaridade dos itens. Por fim, os itens foram analisados por dois especialistas em pesquisa e atuação profissional em auditoria e perícia. A relação das questões é apresentada na Tabela 2, com a indicação das principais atribuições de origem.

\section{Tabela 2}

Questionário Estruturado Aplicado

\begin{tabular}{|c|c|}
\hline $\mathbf{Q}$ & Descrição da Questão \\
\hline $1-$ & Capacidade de agir bem sob pressão (Davis, Farrel, \& Ogilby, 2009) \\
\hline $2-$ & Capacidade de agir com abnegação / ceticismo (Davis et al., 2009; Silva, 2014) \\
\hline $3-$ & Capacidade de agir com assertividade / confiança (Davis et al., 2009; Silva, 2014) \\
\hline 4- & Capacidade de agir com educação, disciplina e lealdade (Silva, 2014) \\
\hline 5- & $\begin{array}{l}\text { Capacidade de agir com honestidade, com postura ética e profissional (Alberto, 2012; Davis et al., 2009; } \\
\text { Silva, 2014) }\end{array}$ \\
\hline & $\begin{array}{l}\text { Capacidade de agir com imparcialidade, de forma a auxiliar o MPF na sua função de fiscal da lei (Alberto, } \\
\text { 2012; Silva, 2014) }\end{array}$ \\
\hline & $\begin{array}{l}\text { Capacidade de agir com meticulosidade e perspicácia (Davies et al., 2009; Sá, 2011; Gonçalves et al. 2014; } \\
\text { Silva, 2014) }\end{array}$ \\
\hline & $\begin{array}{l}\text { Capacidade de agir com persistência, demonstrando interesse e comprometimento com o trabalho (Davis } \\
\text { et al., 2009; Okoye \& Jogu, 2010; Silva, 2014) }\end{array}$ \\
\hline & $\begin{array}{l}\text { Capacidade de agir com responsabilidade, zelo, discrição e manter sigilo (Davis et al., 2009; Okoye \& } \\
\text { Jogu, 2010; Alberto, 2012; Silva, 2014) }\end{array}$ \\
\hline & Capacidade de agir proativamente (Silva, 2014) \\
\hline $11-$ & Capacidade de se adaptar a mudanças (Davis et al., 2009) \\
\hline & $\begin{array}{l}\text { Capacidade de trabalhar em equipe / manter bom relacionamento interpessoal (Davis et al., 2009; Silva, } \\
\text { 2014) }\end{array}$ \\
\hline & Capacidade de ser criativo (Davies et al., 2009; Okoye \& Jogu, 2010) \\
\hline & Capacidade de atuar segundo normas e regulamentos vigentes no MPF (adaptado de Silva, 2014) \\
\hline & $\begin{array}{l}\text { Capacidade de se atualizar por meio de ações que visem o aprendizado contínuo, buscando constantemente } \\
\text { preparo profissional, de modo a maximizar o desempenho competente de suas atribuições (Silva, 2014) }\end{array}$ \\
\hline & Capacidade de pensar como um “malfeitor” (Hegazy, Sangster, \& Kotb, 2017) \\
\hline & Capacidade de agir intuitivamente (Davis et al., 2009) \\
\hline & Conhecimento em legislação e sistema jurídico (Okoye \& Jogu, 2010; Silva, 2014; Hegazy et al., 2017) \\
\hline $19-$ & Conhecimentos em técnicas de investigação de fraude (Okoye \& Jogu, 2010; Hegazy et al., 2017) \\
\hline
\end{tabular}


Ariel Prates, Jonatas Dutra Sallaberry, Leonardo Flach, Ivam Ricardo Peleias e Romina Batista de Lucena de Souza

20- Conhecimentos em informática, utilizando softwares e programas informatizados; e em TI (Silva, 2014)

21- Conhecimentos de auditoria (Hegazy et al., 2017)

22- Conhecimentos em estatística e matemática financeira (pré-teste)

23- Conhecimentos em contabilidade fiscal e tributária (pré-teste)

24- Conhecimentos em contabilidade pública (pré-teste)

25- Capacidade de análise dedutiva (Okoye \& Jogu, 2010; Hegazy et al., 2017)

26- Capacidade de entrevista e testemunho (Davis et al., 2009; Hegazy et al., 2017)

27- Capacidade de pensamento crítico e estratégico (Okoye \& Jogu, 2010; Hegazy et al., 2017)

28- Capacidades para resolução de problemas desestruturados (casos sem precedentes / "novos") (Hegazy et al., 2017)

29- Capacidade de expressar ideias com base em conhecimentos técnicos especializados (Okoye \& Jogu, 2010; Silva, 2014)

30- Capacidade de argumentação (pré-teste)

31- Capacidade de comunicação oral eficaz (Okoye \& Jogu, 2010; Hegazy et al., 2017)

32- Capacidade analítica e de interpretar informações (Davis et al., 2009; Okoye \& Jogu, 2010; Hegazy et al., 2017)

33- Capacidade de planejamento e gerenciamento de informações (Okoye \& Jogu, 2010; Silva, 2014)

34- Capacidade de ser conciso/exato (Davis et al., 2009; Silva, 2014)

35- Capacidade de ser claro e objetivo ao fornecer informações específicas de sua área de conhecimento, facilitando o entendimento para as partes interessadas (Davis et al., 2009; Silva, 2014)

36- Capacidade de transformar dados isolados em informações úteis de forma tempestiva, analisando o contexto de atuação e sua finalidade (Silva, 2014)

37- Capacidade de gerar resultados eficientes e de qualidade, otimizando variáveis relacionadas a tempo, custo, recursos e materiais, economizando-os e utilizando-os de maneira racional (Silva, 2014)

Fonte: Davis et al. (2009), Okoye e Jugu (2010), Sá (2011), Alberto (2012), Gonçalves et al. (2014), Silva (2014), Hegazy et al. (2017) e pré-teste.

Para a análise dos dados, adotou-se a estatística descritiva, com a análise da média e de desvio-padrão, sobre a importância e domínio atribuídos pela amostra.

\section{Análise dos Dados}

Nessa seção são apresentados os dados da pesquisa, bem como sua respectiva análise. A Tabela 3 mostra o ranking das competências, organizadas da maior importância para a menor, com a média e desvio-padrão de importância e domínio.

\section{Tabela 3}

Ranking de competências pela maior média de importância e menor valor desvio-padrão

\section{COMPETÊNCIA}

Capacidade de agir com honestidade, com postura ética e profissional

Capacidade de agir com responsabilidade, zelo, discrição e manter sigilo

Capacidade de agir com educação, disciplina e lealdade

Capacidade de se atualizar por meio de ações que visem o aprendizado contínuo,

buscando constantemente preparo profissional, de modo a maximizar o

desempenho competente de suas atribuições**

Capacidade de gerar resultados eficientes e de qualidade, otimizando variáveis

relacionadas a tempo, custo, recursos e materiais, economizando-os e utilizando-

os de maneira racional

Capacidade de transformar dados isolados em informações úteis de forma

tempestiva, analisando o contexto de atuação e sua finalidade

Importância Domínio

Capacidade de ser claro e objetivo ao fornecer informações específicas de sua área

de conhecimento, facilitando o entendimento para as partes interessadas

\begin{tabular}{cccc} 
Média & DV & Média & DV \\
\hline 7,00 & 0,00 & 7,00 & 0,00 \\
6,92 & 0,28 & 6,77 & 0,44 \\
6,77 & 0,60 & 6,62 & 0,77 \\
\hline 6,62 & 0,65 & 5,31 & 1,55 \\
\hline 6,62 & 0,65 & 5,85 & 0,80 \\
\hline 6,54 & 0,66 & 5,62 & 0,77 \\
\hline 6,54 & 0,78 & 5,77 & 0,73
\end{tabular}

Revista Ambiente Contábil - UFRN - Natal-RN. v. 12, n. 1, p. 215 - 233, Jan./Jun. 2020, ISSN 2176-9036. 
Ariel Prates, Jonatas Dutra Sallaberry, Leonardo Flach, Ivam Ricardo Peleias e Romina Batista de Lucena de Souza

Capacidade de atuar segundo normas e regulamentos vigentes no MPF

Capacidade de agir com imparcialidade

$6,54 \quad \begin{array}{llll}0,97 & 6,31 & 1,03\end{array}$

Conhecimentos de técnicas de investigação de fraudes**

Capacidade analítica e de interpretar informações

Capacidade de expressar ideias com base em conhecimentos técnicos

especializados**

\begin{tabular}{|c|c|c|c|c|}
\hline Capacidade de agir com assertividade e confiança & 6,23 & 1,01 & 5,54 & 0,97 \\
\hline Capacidade de argumentação & 6,23 & 1,01 & 5,46 & 0,66 \\
\hline Capacidade de agir bem sob pressão & 6,08 & 0,95 & 5,77 & 1,09 \\
\hline Capacidade de ser conciso e exato & 6,08 & 1,04 & 5,38 & 0,65 \\
\hline $\begin{array}{l}\text { Capacidade de agir capacidade de agir com persistência, demonstrando interesse } \\
\text { e comprometimento com o trabalho }\end{array}$ & 6,08 & 1,12 & 5,46 & 0,97 \\
\hline Capacidade de agir com meticulosidade e perspicácia & 6,00 & 1,22 & 5,46 & 0,88 \\
\hline Conhecimento das legislações pertinentes e do sistema jurídico** & 6,00 & 1,35 & 4,92 & 0,76 \\
\hline Capacidade de resolver problemas desestruturados/casos novos & 5,92 & 0,95 & 5,00 & 0,82 \\
\hline Conhecimentos em contabilidade pública & 5,77 & 0,93 & 5,38 & 1,12 \\
\hline Capacidade de planejamento e gerenciamento de informações & 5,77 & 0,93 & 5,00 & 1,00 \\
\hline Capacidade de análise dedutiva & 5,77 & 1,01 & 5,38 & 0,77 \\
\hline Capacidade de agir com abnegação e ceticismo & 5,77 & 1,09 & 5,38 & 1,12 \\
\hline Capacidade de se adaptar a mudanças & 5,77 & 1,09 & 5,62 & 0,77 \\
\hline Capacidade de pensamento crítico e estratégico & 5,69 & 0,85 & 5,00 & 1,00 \\
\hline Conhecimentos de auditoria & 5,69 & 0,95 & 4,92 & 1,38 \\
\hline Capacidade de pensar como um "malfeitor"** & 5,69 & 1,11 & 4,62 & 1,50 \\
\hline Capacidade de trabalhar em equipe e manter bom relacionamento interpessoal* & 5,69 & 1,75 & 6,31 & 0,75 \\
\hline Capacidade de agir proativamente* & 5,69 & 1,75 & 5,69 & 0,95 \\
\hline Capacidade de agir intuitivamente & 5,62 & 1,19 & 4,69 & 1,25 \\
\hline $\begin{array}{l}\text { Conhecimentos em informática, utilizando softwares e programas } \\
\text { informatizados; e em TI }\end{array}$ & 5,54 & 1,56 & 4,92 & 0,95 \\
\hline Capacidade de ser criativo & 5,46 & 1,27 & 5,00 & 1,22 \\
\hline Conhecimentos em matemática financeira e em estatística & 5,31 & 1,38 & 4,92 & 1,26 \\
\hline Conhecimentos em contabilidade fiscal e tributária & 5,15 & 1,52 & 4,69 & 1,44 \\
\hline Capacidade de comunicação oral eficaz & 4,77 & 1,69 & 4,31 & 1,44 \\
\hline Capacidade de entrevista e testemunho & 3,92 & 1,61 & 3,46 & 1,71 \\
\hline
\end{tabular}

Capacidade de entrevista e testemunho

$\begin{array}{llll}6,54 & 1,13 & 6,46 & 0,66\end{array}$

\begin{tabular}{llll}
6,46 & 0,66 & 4,62 & 1,56 \\
\hline
\end{tabular}

\begin{tabular}{llll}
6,31 & 0,75 & 5,69 & 0,75 \\
\hline
\end{tabular}

$6,31 \quad 0,95 \quad 5,15 \quad 0,80$

Capacidade de argumentação

Capacidade de ser conciso e exato

e comprometimento com o trabalho

Fonte: Dados da pesquisa.

Como pode-se depreender, das 37 competências, em apenas três delas (*) o domínio por parte da amostra é igual ou superior à importância atribuída a ela, 29 possuem domínio até 1 nível inferior, e cinco possuem diferença superior a um nível entre esses dois quesitos $(* *)$. Dessas cinco, quatro delas possuem "muito elevada importância", o que indica uma necessidade preponderante de capacitar os analistas especialmente nesses quesitos. Das cinco competências mais importantes, quatro são comportamentais, ressaltando a postura e a atitude desses profissionais, semelhante ao encontrado por Silva (2014).

A conduta idônea desses analistas, reforçados por atuar em um órgão fiscalizador e que promove a justiça, está respaldado nos resultados encontrados, com a capacidade de agir com honestidade, com postura ética e profissional tendo importância e domínios máximos $(7,00)$; a capacidade de agir com responsabilidade, zelo, discrição e manter sigilo (importância e domínio 6,92 e 6,77, respectivamente); e a capacidade de agir com educação, disciplina e lealdade (média 6,77 para importância e 6,62 para domínio).

A competência com menor nível de importância é a "capacidade de entrevista e testemunho", considerada de alta importância para contadores forenses nos Estados Unidos e no Reino Unido. Esse resultado demonstra uma atuação distinta dos analistas da área pericial contábil do MPF se comparados com os contadores forenses de outros países. Outra evidência 
Ariel Prates, Jonatas Dutra Sallaberry, Leonardo Flach, Ivam Ricardo Peleias e Romina Batista de Lucena de Souza

disso é o baixo domínio médio obtido pelos analistas sobre tal competência, demonstrando a pouca necessidade de entrevistar pessoas e prestar testemunho na corte.

Semelhante a isso, a "capacidade de comunicação oral eficaz" possui importância e domínio elevados (4,77 e 4,31, respectivamente), mas sensivelmente abaixo das demais. Esse resultado, em conjunto com a "capacidade de entrevista e testemunho" e o alto desvio-padrão da "capacidade de trabalhar em equipe e manter bom relacionamento interpessoal" indicam que tais analistas trabalham com baixa troca de informações orais, limitando-se à troca de informações pela escrita. Essa capacidade obteve o maior desvio-padrão $(1,75)$ no que se refere à importância, e a única com domínio maior que a importância (6,31 e 5,69, respectivamente). Isto sugere que há divergências entre o método de trabalho dos analistas: alguns preferem atuar isoladamente, enquanto outros valorizam a troca de experiências e a ajuda de seus colegas. Contudo, pelo alto domínio, pode-se verificar que há bom relacionamento interpessoal entre esses analistas.

Ao comparar a diferença entre os níveis médios de importância e de domínio, resta evidente que a maioria das competências abordadas possui domínio inferior à importância, denotando um gap de desenvolvimento de competências. Para evidenciar isso, apresenta-se a Tabela 4.

\section{Tabela 4}

\section{Ranking de competências pela diferença entre a importância média e o domínio médio}

\begin{tabular}{|c|c|}
\hline COMPETÊNCIA & Diferença \\
\hline Conhecimentos de técnicas de investigação de fraudes & 1,85 \\
\hline $\begin{array}{l}\text { Capacidade de se atualizar por meio de ações que visem o aprendizado contínuo, buscando } \\
\text { constantemente preparo profissional, de modo a maximizar o desempenho competente de suas } \\
\text { atribuições }\end{array}$ & 1,31 \\
\hline Capacidade de expressar ideias com base em conhecimentos técnicos especializados & 1,15 \\
\hline Conhecimento das legislações pertinentes e do sistema jurídico & 1,08 \\
\hline Capacidade de pensar como um "malfeitor" & 1,07 \\
\hline $\begin{array}{l}\text { Capacidade de transformar dados isolados em informações úteis de forma tempestiva, analisando o } \\
\text { contexto de atuação e sua finalidade }\end{array}$ & 0,92 \\
\hline Capacidade de resolver problemas desestruturados/casos novos & 0,92 \\
\hline Capacidade de agir intuitivamente & 0,92 \\
\hline $\begin{array}{l}\text { Capacidade de gerar resultados eficientes e de qualidade, otimizando variáveis relacionadas a tempo, } \\
\text { custo, recursos e materiais, economizando-os e utilizando-os de maneira racional }\end{array}$ & 0,77 \\
\hline $\begin{array}{l}\text { Capacidade de ser claro e objetivo ao fornecer informações específicas de sua área de conhecimento, } \\
\text { facilitando o entendimento para as partes interessadas }\end{array}$ & 0,77 \\
\hline Capacidade de argumentação & 0,77 \\
\hline Capacidade de planejamento e gerenciamento de informações & 0,77 \\
\hline Conhecimentos de auditoria & 0,77 \\
\hline Capacidade de agir com assertividade e confiança & 0,69 \\
\hline Capacidade de pensamento crítico e estratégico & 0,69 \\
\hline Capacidade de ser conciso e exato & 0,69 \\
\hline Capacidade analítica e de interpretar informações & 0,62 \\
\hline $\begin{array}{l}\text { Capacidade de agir capacidade de agir com persistência, demonstrando interesse e comprometimento } \\
\text { com o trabalho }\end{array}$ & 0,62 \\
\hline Conhecimentos em informática, utilizando softwares e programas informatizados; e em TI & 0,62 \\
\hline Capacidade de agir com meticulosidade e perspicácia & 0,54 \\
\hline Capacidade de ser criativo & 0,46 \\
\hline Conhecimentos em contabilidade fiscal e tributária & 0,46 \\
\hline Capacidade de comunicação oral eficaz & 0,46 \\
\hline Capacidade de entrevista e testemunho & 0,46 \\
\hline
\end{tabular}


Ariel Prates, Jonatas Dutra Sallaberry, Leonardo Flach, Ivam Ricardo Peleias e Romina Batista de Lucena de Souza

\begin{tabular}{lr} 
Conhecimentos em contabilidade pública & 0,38 \\
\hline
\end{tabular}

\begin{tabular}{lc}
\hline Capacidade de análise dedutiva & 0,38
\end{tabular}

\begin{tabular}{ll}
\hline Capacidade de agir com abnegação e ceticismo & 0,38
\end{tabular}

$\begin{array}{ll}\text { Conhecimentos em matemática financeira e em estatística } & 0,38\end{array}$

\begin{tabular}{lc}
\hline Capacidade de agir bem sob pressão & 0,31
\end{tabular}

\begin{tabular}{lc}
\hline Capacidade de atuar segundo normas e regulamentos vigentes no MPF & 0,23
\end{tabular}

$\begin{array}{lc}\text { Capacidade de agir com responsabilidade, zelo, discrição e manter sigilo } & 0,15\end{array}$

$\begin{array}{lc}\text { Capacidade de agir com educação, disciplina e lealdade } & 0,15\end{array}$

$\begin{array}{ll}\text { Capacidade de se adaptar a mudanças } & 0,15\end{array}$

$\begin{array}{ll}\text { Capacidade de agir com imparcialidade } & 0,08\end{array}$

$\begin{array}{ll}\text { Capacidade de agir proativamente } & 0,00\end{array}$

\begin{tabular}{lc}
\hline Capacidade de agir com honestidade, com postura ética e profissional & 0,00 \\
\hline
\end{tabular}

Capacidade de trabalhar em equipe e manter bom relacionamento interpessoal $\quad-0,62$

Fonte: Dados da pesquisa.

Dessa forma, constata-se que há uma necessidade de se aprimorar as competências necessárias ao desempenho profissional dos analistas da área pericial contábil lotados no MPF. As exceções seriam para as capacidades de: agir proativamente; agir com honestidade, com postura ética e profissional; trabalhar em equipe e manter bom relacionamento interpessoal.

Os resultados encontrados indicam sinceridade nas respostas, haja vista que, na maioria das perguntas, as competências foram consideradas mais importantes do que o respectivo domínio. Sob outra perspectiva, os analistas admitiram que há diversos pontos de melhoria, evidenciado pela "capacidade de se atualizar por meio de ações que visem o aprendizado contínuo, buscando constantemente preparo profissional, de modo a maximizar o desempenho competente de suas atribuições", com importância atribuída mais elevada do que o domínio.

Uma das maneiras de se evidenciar a relação entre a importância e o domínio de competências é utilizando um gráfico de dispersão em um plano cartesiano com variáveis "importância" e "desempenho" (Hair Jr. et al., 2005). Diante disso, adaptou-se o gráfico para mostrar a relação importância-domínio, semelhante ao estudo de Silva (2014). Na Figura 1, o eixo horizontal do gráfico refere-se à média da importância e o eixo vertical à média do domínio. 


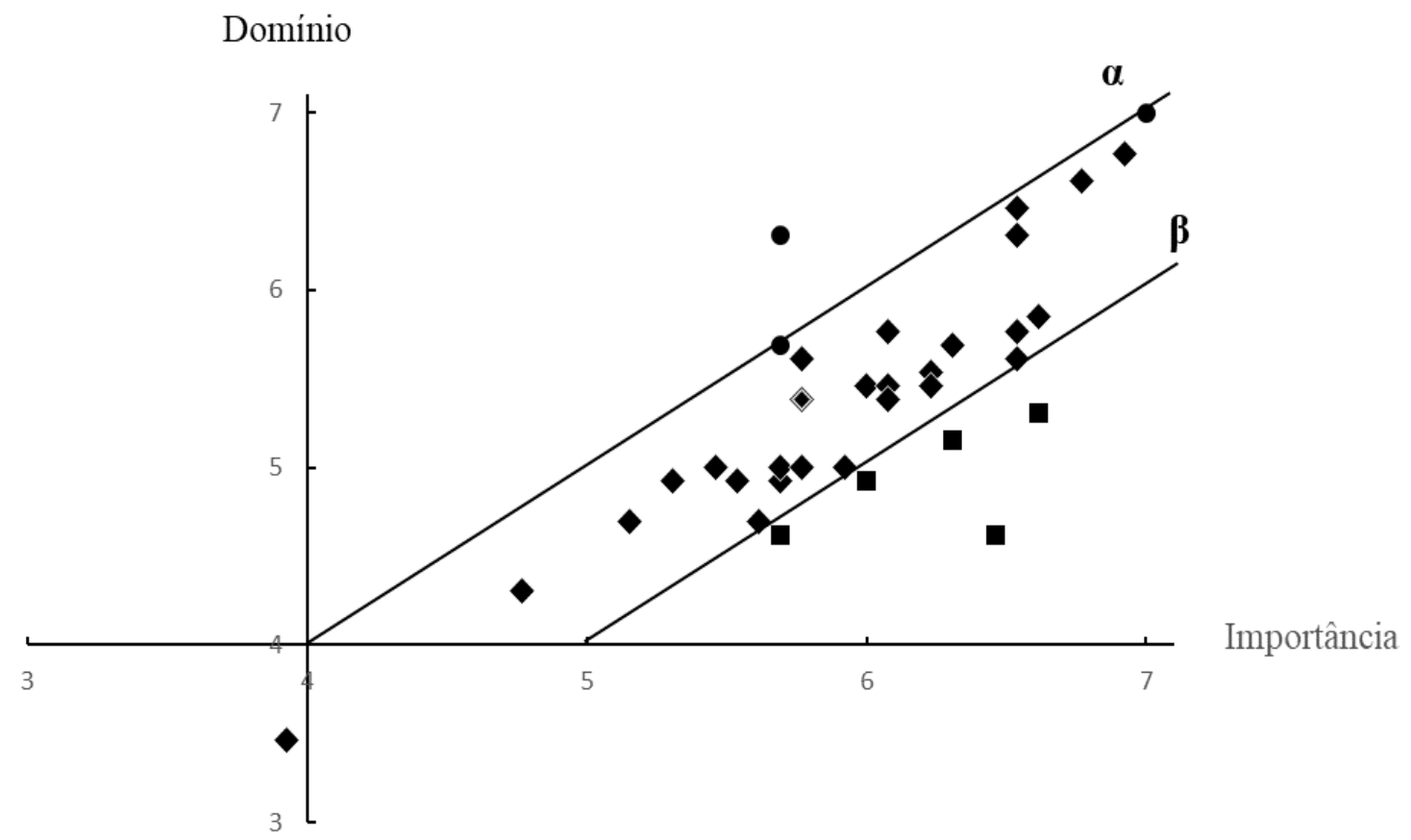

Figura 1 Gráfico de distribuição das competências

Fonte: dados da pesquisa.

O campo sobre ou acima da diagonal $\alpha$ representa as competências cujo domínio está, respectivamente, igual ou superior à importância. Nessa situação, há três competências (representadas por círculos). Abaixo dessa diagonal, e acima da diagonal $\beta$, encontram-se 29 competências com domínio entre 0,01 e 1 nível abaixo da importância atribuída, representadas por losangos. Abaixo da diagonal $\beta$ estão as cinco competências com domínio pelo menos 1,01 nível abaixo da importância média verificada, representada por quadrados.

Assim, as competências representadas por esses quadrados indicam onde há maior necessidade por capacitação, tendo em vista as diferenças significativas. Enquanto no estudo de Silva (2014) não houve competências com diferenças acima de 0,44 (menos de meio nível), no presente estudo percebe-se que há maior necessidade de aprimoramento profissional por parte dos analistas da amostra, haja vista que 20 competências possuem diferença superior a 0,50 , das quais cinco são superiores a 1,00 e consideradas de alta importância ou mais conforme Tabela 5 . 
Ariel Prates, Jonatas Dutra Sallaberry, Leonardo Flach, Ivam Ricardo Peleias e Romina Batista de Lucena de Souza

Tabela 5

Relação de competências com maior necessidade de aprimoramento

\begin{tabular}{lllc}
\hline \multicolumn{1}{c}{ Competência } & \multicolumn{1}{c}{$\begin{array}{c}\text { Importância } \\
\text { Diferença } \\
\text { (Importância } \\
\text { Domínio) }\end{array}$} \\
\hline $\begin{array}{l}\text { Capacidade de se atualizar por meio de ações que visem } \\
\text { o aprendizado contínuo, buscando constantemente } \\
\text { preparo profissional, de modo a maximizar o desempenho } \\
\text { competente de suas atribuições }\end{array}$ & $\begin{array}{l}6,62 \text { (muito elevada importância, } \\
\text { tendendo a extrema importância) }\end{array}$ & 1,31 \\
\hline Conhecimentos de técnicas de investigação de fraudes & 6,46 (muito elevada importância) & 1,85 \\
\hline $\begin{array}{l}\text { Capacidade de expressar ideias com base em } \\
\text { conhecimentos técnicos especializados }\end{array}$ & 6,31 (muito elevada importância) & 1,15 \\
\hline $\begin{array}{l}\text { Conhecimento das legislações pertinentes e do sistema } \\
\text { jurídico }\end{array}$ & 6,00 (muito elevada importância) & 1,08 \\
\hline Capacidade de pensar como um "malfeitor" & $\begin{array}{l}\text { 5,69 (elevada importância, } \\
\text { tendendo a muito elevada }\end{array}$ & 1,07 \\
\hline
\end{tabular}

Fonte: dados da pesquisa.

Os resultados obtidos sugerem que, ao se propor um modelo de desenvolvimento profissional, essas cinco competências seriam as principais a serem aprimoradas, devido a grande diferença entre os níveis médios de domínio e importância. De maneira geral, as competências comportamentais (representadas pela letra A da tríade CHA) possuem maior importância e maior domínio se comparadas às técnicas (letras $\mathrm{C}$ e $\mathrm{H}$ da referida sigla), o que converge para os identificados por Silva (2014). Outro resultado obtido é a percepção de que diversas competências inerentes, tanto a peritos contábeis, quanto a contadores forenses, são necessárias e importantes para os analistas da área de perícia e especialidade em contabilidade.

\section{Considerações Finais}

Esta pesquisa teve como objetivo analisar as competências dos analistas da área pericial contábil lotados no Ministério Público Federal (MPF), de forma a apresentar por nível de importância aquelas que possuem maior necessidade de aprimoramento. Valendo-se de um questionário estruturado de 37 questões fechadas e operacionalizado por escala tipo Likert de sete pontos, aplicou-se tal ferramenta para 13 analistas desse órgão, a fim de verificar a importância e o domínio que a amostra atribuía para as competências apresentadas.

A partir dos resultados, constatou-se que as competências comportamentais possuem, no geral, maior importância e maior domínio em comparação às competências técnicas. Destaca-se como pontos positivos a capacidade de agir com honestidade, com postura ética e profissional, com média máxima $(7,00)$ para a importância e o domínio; a capacidade de agir com responsabilidade, zelo, discrição e manter sigilo, com importância 6,92 e domínio 6,77; e a capacidade de agir com educação, disciplina e lealdade, cuja importância média atribuída foi de 6,77 e domínio médio de 6,62.

Sob outra perspectiva, as competências técnicas possuem, em média, importância e domínio mais baixos. Nesse sentido, destaca-se a capacidade de comunicação oral eficaz, com importância média de 4,77 e domínio 4,31; e a capacidade de entrevista e testemunho, com 3,92 e 3,46, respectivamente. Tendo em vista que são competências oriundas de pesquisas sobre contadores forenses americanos e britânicos, conclui-se que, diante da disparidade de relevância para esses aspectos, as atuações desses profissionais são diferentes quando comparados com os 
analistas periciais contábeis brasileiros, o que se deve aos marcos regulatórios de suas atuações e até mesmo da cultura regional.

Como pontos favoráveis, tem-se que três competências possuem domínio igual ou superior à importância atribuída: as capacidades de agir com honestidade, com postura ética e profissional; de trabalhar em equipe e manter bom relacionamento interpessoal; e de agir proativamente. Por outro lado, as outras 34 competências merecem atenção, de forma a fornecer um melhor preparo aos analistas, haja vista que, dessas, cinco possuem grande defasagem no domínio apresentado em comparação à importância atribuída.

Diante da disparidade de níveis nesses aspectos, sugere-se proporcionar mais treinamentos, cursos e capacitações no tocante às técnicas de investigação de fraudes. Paralelo a isso, a "capacidade de se atualizar por meio de ações que visem o aprendizado contínuo, buscando constantemente preparo profissional, de modo a maximizar o desempenho competente de suas atribuições" também possui relação negativa entre importância e domínio. Assim, infere-se que os analistas da área pericial contábil do MPF deveriam também buscar aprimorar a própria capacitação.

De maneira geral, as competências mais importantes para tais analistas são aquelas voltadas à conduta do profissional, relacionadas à honestidade, responsabilidade e educação, resultados semelhantes aos encontrados por Silva (2014). Assim, resta clara a conduta idônea desses profissionais, muitas vezes relacionadas ao fato de trabalharem em um órgão que visa promover a justiça.

Como limitação, tem-se que menos da metade da população aceitou participar da pesquisa, o que limita a possibilidade de que os resultados obtidos possam ser aplicados para a população com menor margem de erro e maior índice de confiança. Para pesquisas futuras, sugere-se a aplicação de um questionário buscando verificar quais as maiores dificuldades encontradas por esses profissionais em seu desempenho profissional, ou o momento/frequência com que determinada competência é requerida. Também se sugere a replicação dessa pesquisa para profissionais de outras unidades forenses.

\section{Referências}

Alberto, V. L. P. (2012). Perícia contábil (5a ed.) São Paulo: Atlas.

Bervian, P. A., Cervo, A. L., \& Silva, R. (2007). Metodologia Científica (6a ed.). São Paulo: Pearson Prentice Hall.

Boyatzis, R. E. (1982). The competent manager: A model for effective performance. John Wiley \& Sons.

Brandão, H. P. (2009). Aprendizagem, contexto, competência e desempenho: um estudo multinivel. Tese de Doutorado em Psicologia Social. Universidade de Brasília, Brasília, Brasil. Recuperado em 29 abril, 2018, de https://bit.ly/2KvsOwB

Brasil. Constituição da República Federativa do Brasil (1988). Brasília, DF. Recuperado em 5 maio, 2019, de http://www.planalto.gov.br/ccivil_03/constituicao/constituicao.htm 
Ariel Prates, Jonatas Dutra Sallaberry, Leonardo Flach, Ivam Ricardo Peleias e Romina Batista de Lucena de Souza

Brasil. Lei complementar n. 75 de 20 de maio de 1993 (1993). Dispõe sobre a organização, as atribuições e o estatuto do Ministério Público da União. Brasília, DF. Recuperado em 31 janeiro, 2019, de https://bit.ly/1xV3upj

Brasil. Portaria PGR/MPUn. 302 de 24 de maio de 2013 (2013). Atribuições básicas e comuns e os requisitos de investidura nos cargos das Carreiras de Analista e Técnico do Ministério Público da União. Brasília - DF. Recuperado em 5 janeiro, 2018, de https://bit.ly/2tALm7S

Brasil. Ministério Público Federal (2017a). Fiscal da lei, cível e criminal. Brasília - DF. Recuperado em 6 março, 2017, de https://bit.ly/2KgBVVK

Brasil. Ministério Público Federal (2017b). Planejamento Estratégico Institucional. Brasília DF. Recuperado em 13 setembro, 2017, de https://bit.ly/2KtNKqW

Carbone, P. P., Brandão, H. P., \& Leite, J. B. D. (2009). Gestão por competências e gestão do conhecimento ( $3 \mathrm{a}$ ed). Rio de Janeiro: FGV.

CNJ. Conselho Nacional de Justiça (2011). Estudo Comparado sobre Recursos, Litigiosidade e Produtividade. Brasília: Departamento de Pesquisas Judiciárias.

Davis, C., Ramona, F., \& Ogliby, S. (2009). Characteristics and Skills of the Forensic Accountant. US: AICPA. Recuperado em 29 janeiro, 2018, de https://bit.ly/2KgjNep

Durand, T. (1998, June). Forms of incompetence. Proceedings Fourth International Conference on Competence-Based Management. Oslo: Norwegian School of Management.

Fleury, A., \& Fleury, M. T. L. (2004). Estratégias empresariais e formação de competências: um quebra-cabeça caleidoscópio da indústria brasileira. São Paulo: Atlas.

Fleury, M. T. L., \& Fleury, A. (2001). Construindo o conceito de competência. Revista de administração contemporânea, 5(SPE), p.183-196.

Gil, A. C. (2008). Métodos e técnicas de pesquisa social (6a ed.). São Paulo: Atlas.

Gonçalves, P., Machado, M., Machado, L., \& Zanolla, E. (2014). Características do peritocontador: perspectiva segundo juízes da Justiça Federal, advogados da União e peritoscontadores no contexto goiano. Revista Contemporânea de Contabilidade. v.11, n.22), p.119140. doi:https://doi.org/10.5007/2175-8069.2014v11n22p119

Hair, J., Babin, B., Money, A., \& Samouel, P. (2005). Fundamentos de métodos de pesquisa em administração. Porto Alegre: Bookman.

Hegazy, S., Sangster, A. \& Kotb, A. (2017). Mapping Forensic Accounting in the UK. Journal of International Accounting Auditing and Taxation. v.28, p.43-56.

Recuperado em 19 abril, 2017, de https://bit.ly/2Na9EOf 
Ariel Prates, Jonatas Dutra Sallaberry, Leonardo Flach, Ivam Ricardo Peleias e Romina Batista de Lucena de Souza

Huatuco, I. G. B. Contabilidad Forense. Recuperado em 28 abril, 2017, de https://bit.ly/2Kd76RH

Leitão Junior, L. R., Slomski, V. G., Peleias, I. R., \& Mendonça, J. D. F. (2012). Relevância do Laudo Pericial Contábil na tomada de decisão judicial: Percepção de um juiz. RIC-Revista de Informação Contábil, v.6, n.2, p.21-39. Recuperado em 18 dezembro, 2016, de https://bit.ly/2KxnhbV

Leme, R. (2005). Aplicação prática de gestão de pessoas: mapeamento, seleção, avaliação e mensuração de resultados de treinamento. Rio de Janeiro: Qualitymark.

Magalhães, M. L., \& Borges-Andrade, J. E. (2001). Auto e hetero-avaliação no diagnóstico de necessidades de treinamento. Estudos de psicologia, v.6, n.1), p.33-50. Recuperado em 12 maio, 2017, de https://bit.ly/2lF1zoc

McClelland, D. C. (1973). Testing for competence rather than for intelligence. American psychologist, v.28, n.1. Recuperado em 13 maio, 2017, de https://bit.ly/2My1uPn

McLagan, P. A. (1997). Competencies: The next generation. Training \& development, v.51, n.5), p.40-48. Recuperado em 16 maio, 2017, de https://bit.ly/2tOo2mp

Moscovia, F. (1981). Competência interpessoal no desenvolvimento de gerentes. Revista de administração de empresas, v.21, n.2, p.17-25. Recuperado em 11 maio, 2018, de https://bit.ly/2MuN6Xw

Mossin, H. A. (2005). Comentários ao Código de Processo Penal: à luz da doutrina e da jurisprudência. Barueri, SP: Manole.

Nordhaug, O. (1998). Competence specificities in organizations: a classificatory framework. International Studies of Management \& Organization, v.28,n.1, p.8-29. Recuperado em 4 maio, 2018, de https://bit.ly/2tLBV4M

Emma, O., Cletus, I., \& Akenbor, O. (2009). Forensic Accounting in Developing Economies: Problems and Prospects. The University Advanced Journal, v.1).

Okoye, E. I., \& Akenbor, C. O. (2009, Jul./Sep.). Forensic accounting in developing economies-problem and prospects. The University Advanced Research Journal, n.1, p.1-13. Recuperado em 29 abril, 2018, de https://bit.ly/2yRd4CB

Pierry, F. (2006). Seleção por competências: o processo de identificação de competências individuais para recrutamento, seleção e desenvolvimento de pessoal. São Paulo: Vetor.

Raupp, F. M., \& Beuren, I. M. (2006). Metodologia da Pesquisa Aplicável às Ciências Sociais. In I. M. Beuren (Org.), Como elaborar trabalhos monográficos em contabilidade: teoria e prática. São Paulo: Atlas. 
Ariel Prates, Jonatas Dutra Sallaberry, Leonardo Flach, Ivam Ricardo Peleias e Romina Batista de Lucena de Souza

Reis, V. (2003). A entrevista de seleção com foco em competências comportamentais. Rio de Janeiro: Qualitymark.

Rodrigues, C. V., Silva, M. T. D., \& Truzzi, O. M. S. (2010). Perícia criminal: uma abordagem de serviços. Gestão e Produção, v.17, n.4, p.843-857. Recuperado em 3 dezembro, 2017, de https://bit.ly/2MzjoAC

Ruas, R. L. (2005). Gestão por Competências: uma contribuição à estratégia das organizacionais. In R. L. Ruas, C. S. Antonello, \& L. H. Boff (Orgs.), Os novos horizontes da gestão: aprendizagem organizacional e competências. Porto Alegre: Bookman Sá, A. L. de. Perícia contábil (10a ed.). São Paulo: Atlas.

Santana, C. M. S. de. (1999). A perícia contábil e sua contribuição na sentença judicial: um estudo exploratório. Dissertação de Mestrado em Ciências Contábeis. Universidade de São Paulo, São Paulo, Brasil. Recuperado em 12 outubro, 2017, de https://bit.ly/2KyiaVL

Shippmann, J. S., Ash, R. A., Batjtsta, M., Carr, L., Eyde, L. D., Hesketh, B., \& Sanchez, J. I. (2000). The practice of competency modeling. Personnel psychology, v.53, n.3, p.703-740. Doi: https://doi.org/10.1111/j.1744-6570.2000.tb00220.x

Silva, J. S. da. (2014). A percepção dos peritos criminais federais que atuam em crimes financeiros sobre as competências necessárias para o exercício de suas atividades.

Dissertação de Mestrado em Gestão Empresarial. Escola Brasileira de Administração Pública e de Empresas, Centro de Formação Acadêmica e Pesquisa, Rio de Janeiro, Brasil. Recuperado em 19 setembro, 2016, de https://bit.ly/2KyEGRx

Silva, O. J. de P. (2012a). Vocabulário Jurídico (29a ed.). Rio de Janeiro: Forense.

Silva, R. M. da. (2012). Contabilidade forense no Brasil: uma proposição de metodologia. Dissertação de Mestrado em Controladoria Empresarial. Universidade Presbiteriana Mackenzie, São Paulo, Brasil. Recuperado em 3 março, 2018, de https://bit.ly/2NcRjQy

Veras, R. P. (2006). Os crimes do colarinho branco na perspectiva da sociologia criminal. Dissertação de Mestrado em Direito. Pontifícia Universidade Católica de São Paulo, São Paulo, Brasil. Recuperado em 29 agosto, 2018, de https://bit.ly/2tQtipD 